\title{
Assessment of healthcare worker's implementation of childhood routine immunization in primary healthcare centers in Edo State, Nigeria: A mixed method survey
}

\author{
Noel Ebehiremen Uwaibi, ${ }^{1}$ Francis Osezua Erah ${ }^{2}$ \\ ${ }^{1}$ Department of Community Health, College of Clinical Sciences, Edo University Iyamho, Edo State; \\ ${ }^{2}$ Department of Community Health, Irrua Specialist Teaching Hospital, Irrua, Edo State, Nigeria
}

\begin{abstract}
The role of the health care personnel in the delivery of immunization services is very important in achieving the target of immu-
\end{abstract}

Correspondence: Noel Ebehiremen Uwaibi, Ddepartment of Community Health, College of Clinical Sciences, Edo University Iyamho, Edo State, Nigeria.

E-mail: noel.uwaibi@gmail.com

Key words: Challenges; knowledge; immunization.

Conflict of interest: The authors declare no conflict of interest.

Ethics approval and consent to participate: Ethical clearance to conduct this study was sought and obtained from the Ethical Committee. Permission was sought from the Permanent Secretary, Edo State Hospital Management Board and Chairpersons of the Local Government Areas. Institutional permission were sought and obtained from the Primary Health Care Coordinators, and Heads of the health facilities while Primary health care centers were numbered and coded to maintain confidentiality.

Participants' consent for publication: Written informed consent was obtained from each respondent before conducting interviews, while confidentiality and privacy of each respondent was respected during the interviews. To ensure confidentiality of the respondents, serial numbers rather than names was used to identify the respondents, and interviews were conducted in a private area to allow the respondent speaks freely and ensure privacy. Respondents were informed that they had the right to decline participation or to withdraw from the study at any time they wished with no penalties or loss of benefits. Health education on importance of immunization was given to the healthcare workers, respectively at the end of the interview sessions. Data was stored safely and was made accessible to only the primary researcher and research assistants. Availability of data and materials: The author confirms that the data supporting the findings of this study are available from the corresponding author (Uwaibi N.E) upon reasonable request.

Received for publication: 3 November 2020 .

Revision received: 17 November 2020.

Accepted for publication: 17 November 2020.

This work is licensed under a Creative Commons Attribution NonCommercial 4.0 License (CC BY-NC 4.0).

${ }^{\circ}$ Copyright: the Author(s), 2021

Licensee PAGEPress, Italy

Annals of Clinical and Biomedical Research 2021; 2:117

doi:10.4081/acbr.2021.117 nization coverage of $90 \%$ given by the world Health Organisation (WHO). The objective of the study was to determine the challenges affecting healthcare worker's implementation of immunization services in Primary Healthcare Care (PHC) centres in Edo State, Nigeria. A descriptive cross-sectional study design, with a mixed method of data collection approach (incorporating quantitative and qualitative methods) using an interviewer administered questionnaire among 295 respondents (comprised of 270 health care providers, 7 key informants and 18 supervisors) of immunization activities in the various health care facilities for the Focus Group Discussion (FGD) guide. Ethical clearance for the study was obtained from the Ethics Committee of the University of Benin Teaching Hospital. Quantitative data collected was analyzed using the International Business Machine statistical package for Social Science (IBM) version 21.0 while themes occurring in the qualitative data were analyzed using ATLAS.ti software. Logistic regression was calculated to determine odds ratio and level of significance was set at $<0.05$. This study showed that good knowledge of immunization. age, training on the implementation of immunization, and designation affected their knowledge of immunization, and some of the challenges encountered were insufficient workers and transport for outreach activities, funding and impress, lack of motivation. Health worker's knowledge of immunization was good, majority were trained on implementation on immunization services but there were still numerous challenges such as insufficient workers and transportation which must be addressed to strengthen and improve immunization service delivery.

\section{Introduction}

Immunization promotes better health outcomes in children and increase the chances of child survival if well expanded and implemented. ${ }^{1}$ Strategies that improve the uptake of vaccination include "supply side" interventions such as constant supply of vaccines, strong health system to ensure delivery, Knowledge and sufficient health personnel to administer vaccine, and the "demand side" components which consist of health seeking behavior of household such as building the knowledge base of the mothers. ${ }^{2}$

In Nigeria, Routine Immunization (RI) programs are challenged by factors ranging from access to utilization of immunization services which includes incorrect knowledge, wrong attitude, and poor orientation of health workers, lack of political commitment, beaurocratic bottle-necks, poor donor interest in routine immunization and the overshadowing influence of supplemental immunization activities over routine immunization. ${ }^{3-5}$

Globally, studies have shown that health workers knowledge of routine childhood immunization in developing countries was poor. ${ }^{6}$ With inadequate knowledge come opportunities for error, and such errors give rise to health risks/accidents to children and 
these affect the integrity of the entire immunization program discouraging uptake and therefore reducing RI coverage. In many developing countries like Nigeria, vaccinators in primary health care centers represent the lowest tiers of health workers authorized to provide injections. Under such circumstances, there is task shifting of vaccine administration to community health workers or volunteers, which is not appropriate. ${ }^{7}$ Health workers do not also offer instruction about immunization side effects, and do not communicate pertinent information about vaccines and their importance to mothers/caregivers. This poor communication by health workers can lower adherence rate and low immunization compliance, ${ }^{8,9}$ this will lead to inability of the health workers to recognize and manage Adverse Effect Following Immunization (AEFI), which on the long run lead to fear of RI by mothers and poor immunization coverage and increase incidences of VPDs and worsen child morbidity and mortality.

Despite the growing skill demands for health workers, the same basic approach to immunization training has been in use for more than 30 years. This usually takes the form of short, offsite, inservice training courses, which are often delivered through cascade training by the trainers who may be experts in the subject matter but not in training techniques, or vice versa. ${ }^{7}$ This could invariably affect the quality of routine immunization services provided in the health facilities as the quality of RI services offered is reduced.

In many parts of Nigeria, there is shortage of qualified personnel in Primary Healthcare Centre (PHC) facilities. This has resulted in unavailability of 24-hour services in many PHC facilities. Poor utilization of PHC facilities in favour of unskilled health practitioners has largely contributed to the poor health indices in the country. Utilization of PHC services is directly affected by the readiness of PHC facilities to deliver health services in terms of adequate staffing and equipment. This low level of facility readiness in PHC centres has contributed to poor utilization of PHC services by mothers. ${ }^{10}$

Health workers are important agents in the implementation of immunization programs, therefore poor knowledge of RI could affect their practice can lead to reduce potency of the vaccines and increase Adverse Effects Following Immunization (AEFI). ${ }^{11}$ and when mothers/caregivers are not satisfied with PHC services received at the health care centers, it may lead people to turn to expatriate to higher level hospitals for routine immunization services. ${ }^{3}$ This study will help to find out health workers challenges to implementation of RI. Observed gaps will help to improve service and develop training manual guidelines and modalities for $\mathrm{HCW}$ and PHCs.

\section{Materials and Methods}

The study was carried out in PHC facilities across the three Local Government areas in Benin City, Edo State, Nigeria. Benin city is the capital of Edo State and has 3 LGAs Oredo, Egor, and Ikpoba Okha LGAs (12, 10 and 10 wards respectively). There are 35 government owned PHC facilities in Benin City with 35 PHC centers and immunization services activities are carried out in these PHCs.

A descriptive cross-sectional study design, with a mixed method of data collection (incorporating quantitative and qualitative methods) was utilized for this study. The study population was 295 respondents, (comprised of a total population 270 health care providers, 7 key informants and 18 supervisors) of various Primary Health Care centers was utilized for the 3 Focus Group Discussion (FGD). The sample size was calculated for healthcare providers in the various health facilities using the formula for studying single proportion: ${ }^{12} \mathrm{n}=(\mathrm{Z}) 2 \mathrm{pq}$ (deff)/ d2, where $\mathrm{P}$ was the prevalence of health workers $(88 \%)$, knowledge of benefit of immunization among health care workers in 2014 in Imo State, Nigeria. ${ }^{13}$ A total population of all health care workers who met the inclusion criteria was done in all the 35 PHCs in Benin city.

Quantitative and qualitative tools were used for data collection. A structured interviewer administered questionnaire with closed and open-ended questions was used to collect data. Three FGD involving 6 participants each categorized by rank were carried out with questions targeted at assessing their knowledge and challenges affecting the implementation of immunization. Each FGD was conducted by the researcher and two assistants who simultaneously took notes and did audio recording. The FGD was conducted with a purposeful interactive guide designed to meet the objectives of this study. The sitting arrangement at each session was such that it allowed for easy eye contact and hearing between the principal facilitator and the participants. The participants were encouraged to talk freely and spontaneously. Each discussion lasted for about 60 minutes, manual and audio cassette recordings were done with the consent of respondents. To remove any potential bias, no financial or other incentives was offered to participants, however, transportation expenses were reimbursed. The notes and recordings were transcribed within 48 hours, using thematic analysis to identify recurrent themes in the supervisor's/unit heads responses. Ethical clearance to conduct this study was sought and obtained from the Ethical Committee, University of Benin Teaching Hospital.

\section{Statistical analysis}

The retrieved questionnaires were screened for completeness by the researcher, coded and entered the IBM SPSS version 21.0 software. The categorical data were presented as frequencies and percentages while numerical data that were normal in distribution were expressed as mean and standard deviation. Statistical tests were carried out using the independent student's t-test to compare difference in means of numerical data. The Chi-squared test of association and Fisher's exact test was used in instances where the total expected cell frequencies less than five was more than $20 \%$. The simple logistic regression was applied to calculate Odds Ratio (ORs). The level of significance was set at $p<0.05$. Transcripts from qualitative interviews were read several times by the researcher within 48 hours of the interview to identify themes and categories. ATLAS.ti Vs. was used for coding and analysis of the transcript. The coding was used in analysis of the different themes that emerged from the transcript and triangulation where data obtained from the qualitative interview were compared with those obtained from the qualitative survey in line with the objectives of the study. The findings from the data analyzed were presented in sections using statements, frequency distribution tables and charts/graphs. Information from bivariate analyses were presented using contingency tables. Data obtained using qualitative data collection tools were presented as prose.

\section{Results}

The mean age of the respondents was $41.4 \pm 8.7$ years with a higher proportion $(115,42.6 \%)$ belonging to the $40-49$ years' age group, followed by 84 (31.1\%) aged $30-39$ years, while $48(17.8 \%)$ were aged 50-59 years. A higher proportion were females (180, $66.7 \%)$ while $90(33.3 \%)$ were males. One hundred and three 
(38.1\%) had worked for 4 years or less, 66 (24.4\%) had 5-9 years' experience while 54 (20.0\%) had 10-14 years' experience.

All the healthcare workers knew the age of administration for BCG, OPV, measles and yellow fever $270(100.0 \%)$, and the route of administration for OPV, pentavalent and dose for OPV but only $156(57.8 \%)$ and 189 (70.0) knew the dosage for PCV and pentavalent vaccines (Table 1 and 2).

Table 1. Socio-demographic characteristics of the healthcare workers.

\begin{tabular}{|c|c|c|}
\hline Variable & Frequency & Percent \\
\hline $\begin{array}{l}\text { Age (years) } \\
22 \text {-group } 29 \\
30-39 \\
40-49 \\
50-59\end{array}$ & $\begin{array}{c}23 \\
84 \\
115 \\
48\end{array}$ & $\begin{array}{l}(8.5) \\
(31.1) \\
(42.6) \\
(17.8)\end{array}$ \\
\hline $\begin{array}{l}\text { Sex } \\
\quad \text { Male } \\
\quad \text { Female }\end{array}$ & $\begin{array}{c}90 \\
180\end{array}$ & $\begin{array}{l}(33.3) \\
(66.7)\end{array}$ \\
\hline $\begin{array}{l}\text { Religion } \\
\text { Christianity } \\
\text { Islam }\end{array}$ & $\begin{array}{c}253 \\
17\end{array}$ & $\begin{array}{c}(93.7) \\
(6.3)\end{array}$ \\
\hline $\begin{array}{l}\text { Ethnicity } \\
\text { Benin } \\
\text { Etsako } \\
\text { Urhobo } \\
\text { Esan } \\
\text { Yoruba } \\
\text { Igbo } \\
\text { Others* } \\
\end{array}$ & $\begin{array}{l}109 \\
53 \\
27 \\
24 \\
24 \\
18 \\
15\end{array}$ & $\begin{array}{l}(40.4) \\
(19.6) \\
(10.0) \\
(8.9) \\
(8.9) \\
(6.7) \\
(5.5)\end{array}$ \\
\hline $\begin{array}{l}\text { Designation } \\
\text { JCHEW } \\
\text { SCHEW } \\
\text { CHO } \\
\text { NO/Midwife } \\
\text { PH nurse }\end{array}$ & $\begin{array}{l}63 \\
50 \\
36 \\
59 \\
62\end{array}$ & $\begin{array}{l}(23.3) \\
(18.5) \\
(13.3) \\
(21.9) \\
(23.0)\end{array}$ \\
\hline $\begin{array}{l}\text { Responsibility } \\
\text { Head of unit } \\
\text { Healthcare provider }\end{array}$ & $\begin{array}{c}53 \\
217\end{array}$ & $\begin{array}{l}(19.6) \\
(80.4)\end{array}$ \\
\hline $\begin{array}{l}\text { Work experience (in years) } \\
\quad \begin{array}{l}\leq 4 \\
5-9 \\
10-14 \\
15-19 \\
\geq 20 \\
\text { Total }\end{array}\end{array}$ & $\begin{array}{c}103 \\
66 \\
54 \\
24 \\
23 \\
\mathrm{~N}=270\end{array}$ & $\begin{array}{l}(38.1) \\
(24.4) \\
(20.0) \\
(8.9) \\
(8.5) \\
100\end{array}$ \\
\hline
\end{tabular}

Mean age $=41.4 \pm 8.7$ years. Mean work experience $=8.2 \pm 6.5$ years.
A higher proportion $193(71.5 \%)$ health workers had good knowledge of immunization, only while 4 (1.5\%) had poor knowledge of immunization (Figure 1).

\section{Qualitative data on health workers' knowledge of rou- tine immunization}

Knowledge of routine immunization and its benefit to children

All the supervisors reported knowing the benefits of vaccination, and most of them could name specific diseases against which the vaccines protect their children. A respondent answered as follows:

"Routine immunization is carried out in the health facility and it involves giving antigens like PCV, yellow fever and it is given in order to prevent child diseases. "(48 years-old Community Health Officer)

Other respondents had contrary definitions on routine immunization as one of the participants reported:

"What I tell our mothers is that routine immunization is bodyguards that we give to children to prevent vaccine preventable diseases which are about 8 or 9 example tuberculosis, yellow fever measles etc." (50-years-old nurse)

Two hundred and forty-seven $(91.5 \%)$ healthcare workers had received training on immunization. Of the 247 , about $84(34.0 \%)$ had more than 4 years of training, while $57(23.1 \%)$ had less than

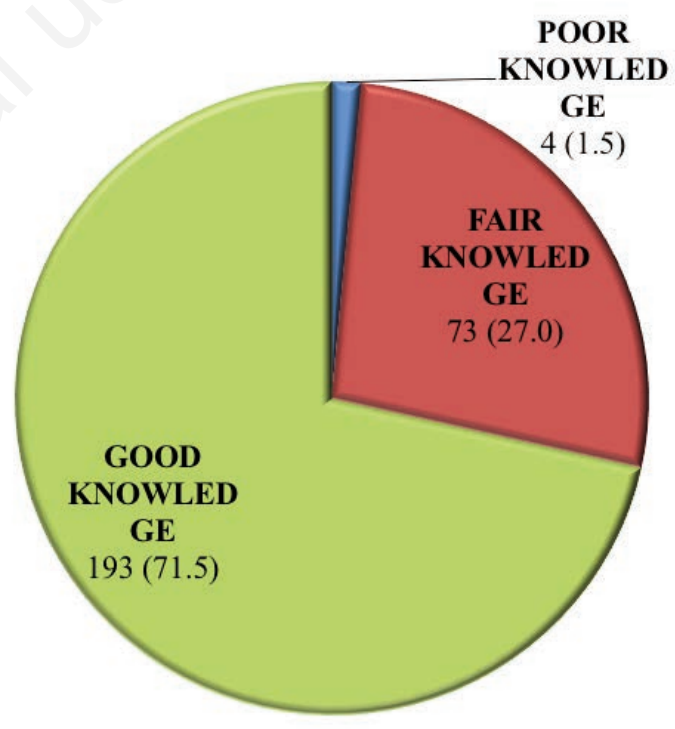

Figure 1. Composite scores for healthcare workers' knowledge of immunization.

Table 2. Knowledge of dosages, appropriate age and route of administration of NPI vaccines among healthcare workers.

\begin{tabular}{lccc} 
Vaccine & Correct dosage & Appropriate age at administration & Correct route of administration \\
$\mathbf{N}=270$ & $\mathbf{N}=270$ & 270 \\
$\mathbf{n}(\%)$ & $(\%)$ & $263(97.4)$ \\
BCG & $199(73.7)$ & $270(100.0)$ & $270(100.0)$ \\
OPV & $270(100.0)$ & $270(100.0)$ & $270(100.0)$ \\
Pentavalent & $189(70.0)$ & $266(98.5)$ & $202(74.8)$ \\
PCV & $156(57.8)$ & $228(84.4)$ & $243(90.0)$ \\
Measles & $220(81.5)$ & $270(100.0)$ & $218(80.7)$ \\
Yellow fever & $202(74.8)$ & $270(100.0)$ & \\
\hline
\end{tabular}


a year of training, $14(5.2 \%)$ reported having prior clinical sessions at their health facilities. Of these, $9(64.3 \%)$ stated that they had at least one session on a vaccine related topic (Table 3 ).

Forty $(47.7 \%)$ of the healthcare workers aged $30-39$ years had good knowledge of injection safety practice compared to 15 (31.3\%) of those aged 50-59 years. This association as well as designation and training on injection practice was statistically significant $(\mathrm{p}=0.036$, Table 4$)$.

Sixty-seven $(37.2 \%)$ of the female workers had good knowledge of injection safety practice compared to 31 (34.4\%) of their male counterparts. This association was not statistically significant $(\mathrm{p}=0.655)$.

\section{Qualitative data on key informant interview}

\section{Challenges faced by health workers when carrying out their duties}

The key informants emphasized the challenges of insufficient workers and lack of transport for outreach activities, ignorance, funding, lack of motivation and irregular/inadequate training on standard of care.

Excerpts revealed that:

"The children tie thread around their necks because they have superstitious believes that it prevents diseases from attacking the child." (52-years-old WHO coordinator)

"Even though it is written in the guidelines that the child can be vaccinated when having fever, providers are very careful and avoid vaccinating them during this time. I don't blame them, because I believe that they have the right to make this decision, because if something goes wrong, the entire fault falls on the health worker. So, they try to avoid any problems and keep themselves protected in some way and I don't think we can blame them for that." (55-years-old state immunization officer)

Another theme that was brought up was accessibility to health care centres:

"A lot of our children are not within this municipal. About 70\% of the children from our target group are not within where we have health facility, and again the policy says if a mother is going to travel outside $5 \mathrm{~km}$ to get to the health facility, the services should be brought nearer to them but because support is not provided by the LGA you find out that most of the children are not being reached." (55-years-old, state immunization officer)

Knowledge of immunization and its adverse effects was another theme that was reported by the key informants. They felt the mothers lacked basic knowledge and needed health education as the tool to reinforce the importance of childhood routine immunization:

"Knowledge about immunization is inadequate. There should be more enlightenment campaign especially on whether there is overdose of immunization or the implication for a child who receives the same immunization at school and at church or health center." (48-years-old, cold chain coordinator Edo State)

Other challenges are ownership of the programme, partnership and poor supervision.

Two key informants reported:
"Ownership of the immunization program is very important. When planning immunization programs there should be community participation. If the community is part of it, the programme will succeed but some health workers will just plan and not involve the community". (42-years-old, local immmunization officer, Oredo)

"Partners are already tired of sponsoring immunization and by the end of this year GAVI, we don't know what to do and it will now be government procuring the vaccine.

Table 3. Healthcare workers' training on immunization.

\begin{tabular}{lcc} 
Variable & Frequency & Percent \\
Receipt of training on immunization & & \\
$\quad$ Yes & 247 & $(91.5)$ \\
$\quad$ No & 23 & $(8.5)$ \\
Duration since last training $(\mathrm{n}=247)$ & 57 & \\
$\quad<1$ year ago & 60 & $(23.1)$ \\
$\quad 1-2$ years ago & 46 & $(24.3)$ \\
$\quad>2-3$ years ago & 84 & $(18.6)$ \\
$\quad \geq 4$ years & 14 & \\
Conduct of health education before immunization sessions & \\
$\quad$ Yes & 256 & $(5.2)$ \\
$\quad$ No & & \\
$\quad$ & $94.8)$ \\
Health education topic related to immunization $(\mathrm{n}=14)$ & \\
$\quad$ Yes & 9 & $(64.3)$ \\
No & 5 & $(35.7)$ \\
Total & 270 & $(100)$ \\
\hline
\end{tabular}

Table 4. Socio-demographic characteristics and knowledge of immunization among healthcare workers

\begin{tabular}{|c|c|c|c|c|}
\hline Variable & $\begin{array}{l}\text { Wledge of s } \\
\text { Poor } \\
\text { n (\%) }\end{array}$ & $\begin{array}{l}\text { fe injection } \\
\text { Good } \\
\text { n (\%) }\end{array}$ & Test & $\begin{array}{l}\text { p value } \\
\text { statistic }\end{array}$ \\
\hline $\begin{array}{c}\text { Age (years) } \\
22-29 \\
30-39 \\
40-49 \\
50-59\end{array}$ & $\begin{array}{l}13(56.5) \\
44(52.4) \\
82(71.3) \\
33(68.8)\end{array}$ & $\begin{array}{l}10(43.5) \\
40(47.6) \\
33(28.7) \\
15(31.3)\end{array}$ & $\chi^{2}=8.572$ & $0.036^{*}$ \\
\hline $\begin{array}{l}\text { Sex } \\
\quad \text { Male } \\
\text { Female } \\
\end{array}$ & $\begin{array}{c}59(65.6) \\
113(62.8)\end{array}$ & $\begin{array}{l}31(34.4) \\
67(37.2)\end{array}$ & $\chi^{2}=0.200$ & 0.655 \\
\hline $\begin{array}{l}\text { Designation } \\
\text { Public health nurse } \\
\text { CHO } \\
\text { Nursing Officer } \\
\text { Midwives } \\
\text { SCHEW } \\
\text { JCHEW }\end{array}$ & $\begin{array}{l}35(56.5) \\
26(72.2) \\
28(75.7) \\
15(68.2) \\
24(48.0) \\
44(69.8)\end{array}$ & $\begin{array}{l}27(43.5) \\
10(27.8) \\
9(24.3) \\
7(31.8) \\
26(52.0) \\
19(30.2)\end{array}$ & $\chi^{2}=11.383$ & $0.044^{*}$ \\
\hline $\begin{array}{l}\text { Responsibility } \\
\text { Head of unit } \\
\text { Healthcare provide }\end{array}$ & $\begin{array}{r}28(52.8) \\
\text { er144 (66.4) }\end{array}$ & $\begin{array}{l}25(47.2) \\
73(33.6)\end{array}$ & $\chi^{2}=3.372$ & 0.066 \\
\hline $\begin{array}{l}\text { Experience (years) } \\
\quad \leq 4 \\
5-9 \\
10-14 \\
15-19 \\
\geq 20\end{array}$ & $\begin{array}{l}55(53.4) \\
49(74.2) \\
35(64.8) \\
16(66.7) \\
17(73.9)\end{array}$ & $\begin{array}{l}48(46.6) \\
17(25.8) \\
19(35.2) \\
8(33.3) \\
6(26.1)\end{array}$ & $\chi^{2}=9.058$ & 0.060 \\
\hline $\begin{array}{l}\text { Training on safe inject } \\
\text { Yes } \\
\text { No }\end{array}$ & $\begin{array}{c}\text { tion practices } \\
0(0.0) \\
172(68.3)\end{array}$ & $\begin{array}{l}18(100.0) \\
80(31.7)\end{array}$ & $2=33.848$ & $<0.001^{*}$ \\
\hline
\end{tabular}

*Significant. 
It is also the partners that go for supervision. The health workers will tell you they don't have vehicles to do supervision of the immunization programs. We will be the one to carry them even if they have vehicles, they will say they don't have fuel". (52-yearsold, WHO co-ordinator Edo State)

\section{Discussion}

Overall, healthcare workers exhibited good knowledge of immunization. Majority of the healthcare workers knew the age of administration of all vaccines, the route of administration while a comparatively smaller proportion knew the dosages. Comparable results were obtained in a study carried out in Oman where almost all the participants knew the proper doses and routes of administration of OPV and BCG vaccination, respectively. ${ }^{14}$ These results are improvements on those reported in Thailand, where only three quarter of the respondents knew the proper dose and routes of administration of BCG, DPT, and HBV vaccines. ${ }^{15}$ Most of the respondents knew VPDs in the process of eradication or elimination of some diseases. The performance of the health workers may be due to repeated training sessions which are carried out routinely especially before immunization-plus days, as reinforcement of such information improves knowledge of immunization.

A large proportion of the healthcare workers thought that mild fever was the most important vaccination barrier. Though fever with a temperature of $\geq 40.5^{\circ} \mathrm{C}$ is a factor to be taken into account is not however a contraindication. ${ }^{16}$ This perception could have far reaching implications as it could contribute to prevalence of missed opportunities and incomplete immunization in Benin City as most mothers maybe afraid to bring their children for immunization due to the anticipated side effect. Inadequate knowledge of important issues such as contraindications to vaccination by health workers may result in transfer of false information to clients as healthcare workers are the major source of information for caregivers regarding immunization. There is therefore the need to streamline the contents of interventions provided by healthcare workers.

In this study, healthcare workers' age, designation, years of experience in immunization practice at PHC level and previous attendance of immunization training had significant influences on their knowledge of immunization. Nurses/Midwives/Public Health nursing practitioners had better knowledge compared other categories of health workers. Similar observations were made in a study carried out in Egypt. ${ }^{17}$ This trend is probably due to the fact that nursing/midwifery qualifications have considerable public health academic content making them to be better equipped to work in the PHCs. Nevertheless nurses/midwives who practice at PHC level may still need to seek additional exposure in Public Health, and for those in the lower cadre might need to seek added qualifications, so that they can be better equipped for health promotion and disease prevention services at the grass root levels where they work. In this study there was also a significant association between training on vaccination of the healthcare workers and their knowledge of immunization. This trend has been noted in a study done in Thailand, ${ }^{15}$ where trained healthcare workers had better knowledge compared to their untrained counterparts. To ensure optimal effectiveness in health care service delivery, continuous training and regular supervision on National programme on immunization guidelines and the cold chain system are necessary.

The findings of this study place a lot of emphases on education by healthcare workers as their knowledge of immunization is very important. Training on immunization are usually in-service specif- ically incorporated as part of national immunization campaigns. However less than a tenth of the healthcare workers in this study received training on injection safety. This is similar to findings from a Kaduna based study in 2013, where less than one fifth of the health workers attended training on safe injection practice with regards to routine immunization. ${ }^{18}$ Contrast results were presented in a study from Bangladesh, were none of health workers in the health facilities observed, attended training on injection safety. ${ }^{19}$

Most of the healthcare workers studied received training on immunization with about a third being trained in the preceding four years. This finding is however in variance with the outcome of the qualitative finding in this study were health workers claimed they were constantly trained and miscued their school education as training for immunization.

Absence of regular training could be due to paucity of funds or poor political will on the part of government. Regular training on immunization is recommended as immunization training intervention significantly raises and sustains overall awareness on immunization, as studies carried out in Brazil and Canada have demonstrated knowledge decay after initial training. ${ }^{20,21}$ Education as an intervention is likely to be effective in the short term and can improve the performance of health care providers. However frequent training and retraining of immunization providers by the government and immunization policy makers is important to maintain the standard practice on immunization.

Only one-fifth of the healthcare workers knew the correct WHO definition of injection safety. Similar observations had been noted in a study conducted in Benin City in $2012^{22}$ where the knowledge of injection safety among health workers was found to be poor. Almost all respondent was knowledgeable on pathogens transmitted through unsafe injection practices. In a related study done in Kaduna, Nigeria over three quarters of the HCWs could name HIV/AIDS, HBV and $\mathrm{HCV}$ as pathogens transmitted by unsafe injection practice. ${ }^{15}$ Thus knowledge of specific infections that could result from unsafe injection practices especially HIV and HBV infections was high. Current finding was also consistent with observations made in another study in Ilorin, Nigeria ${ }^{23,24}$ in which over half of the health workers had knowledge of diseases transmissible by unsafe injection practices. Hence, it could be said that there is higher awareness among primary HCWs regarding the risk of disease transmission by unsafe injection practices. The high level of awareness about the mode of transmission of HIV infection may be due to the fear of the disease in the society and increased health education through the mass media concerning the diseases and its mode of spread.

\section{Conclusions}

Majority of the health workers in the primary health care centers had good knowledge of immunization but had a lot of challenges affecting the implementation of immunization services according to the guidelines. Health workers need to be supportive of mothers/caregivers and have a positive attitude towards the caregivers to help improve utilization of immunization services. They should be encouraged to involve themselves in self-development programmes that will improve service delivery skills and help identify the danger signs of vaccine preventable diseases

\section{References}

1. Tagbo BN, Uleanya ND, Nwokoye IC, et al. Mothers' knowl- 
edge, perception, and practice of childhood immunization in Enugu. Niger J Paed 2012;39:90-6.

2. Goldstein S, Macdonad NS, Gurguis S. SAGE working group. Health communication and vaccine hesitancy. Vaccine 2015;33:12-4.

3. Hannan AA. Maternal satisfaction about childhood immunization in primary health centre. Pan Afr Med J 2014;18:157.

4. National Population Commission and ICF International. Nigeria Demographic and Health Survey 2013. Abuja, Nigeria: NPC and ICF International; 2014:92-153

5. Birhanu S, Anteneh A, Kibie Y, Jejaw A. Knowledge, attitude and practice of mothers towards immunization of infants in health centres at Addis Ababa, Ethiopia. Am J Health Res 2015;4:6-17.

6. Saleh JA, Adamu HI, Ningi AI. NNT Elimination and the Nigeria's health system: Where is the missing link? Sci J Public Health 2015:3:417-22.

7. Beaven AA, Atienza BS, Abing VT, et al. Maternal constraints towards compliance to expanded program on immunization. $\mathrm{J}$ Nurs Health Care 2016;3:30-8.

8. Okafor IP, Dolapo CD, Onigbogi OM, Iloabuchi IG. Ruralurban disparities in maternal immunization knowledge and childhood health seeking behaviour in Nigeria: a mixed method study. African Health Sci 2014;14:333-47.

9. Oche MO, Adamu H. Determinants of patients waiting time in the General Outpatients department of a tertiary health institution in north western Nigeria. Ann Med Health Sci 2013;34:588-92.

10. Shen AK, Fields AR, McQuestion MB. The future of routine immunization in the developing world: challenges and opportunities. Global Health Sci Pract 2014;2:381-92.

11. Adebayo BE, Oladokun RE, Akinbami FO. Immunization coverage in a rural community in South-eastern Nigeria. J Vaccines Vaccine 2012;3:143.

12. Cochrane WG. Sampling Techniques, 3rd Edition. New York: John Wiley and Son 1977.

13. Paediatric Association of Nigeria Recommended routine immunization schedule for Nigerian children. Niger J Paed 2012;39:152-58.

14. Al-Ayed IH. Knowledge and practices of childhood immuniza- tion among primary health care providers in Riyadh City: Part I: handling and administration of vaccines. Curr Pediatr Res 2005;9:15-21.

15. Widsanugorn O, Suwattana O, Sakamoto J, Rashid H. Healthcare workers' knowledge and practices regarding expanded program on immunization in Kalasin, Thailand Nagoya J Med Sci 2011; 73:177- 185.

16. National Centre for Immunization and Respiratory Disease. Advisory Committee on Immunization Practices: General Recommendations on Immunization MMWR Recommendations and Reports 2011;60:1-64.

17. Lismail NA, El-Shoubary WA, Mahaba H. Safe injection practice among health workers in gharbiya governorate Eygpt. Eastern Medit Health J 2007;13:897-906.

18. Audu O, Joshua SA, Enokela OP. Knowledge and practice of injection safety among workers of Nigerian Prison service Health facilities in Kaduna State. Am J Public Health Res 2013;1:171-6.

19. Chowdhury KA, Roy T, Faroque BM, Bachar SC, Asaduzzaman M, Nasrin N. A comprehensive situation assessment of injection practices in primary health care hospitals in Bangladesh. BMC Public Health. 2011; 11:779. Doi.10.14712458/11/779.

20. Anderson GS, Gaetz M, Masse J. First aid skill retention of first responders within the workplace. Scand J Trauma Resusc Emerg Med 2011;19:11.

21. Amaral F, Almeida Troncon LE. Retention of knowledge and clinical skills by medical students: a prospective, longitudinal, one-year study using basic pediatric cardiology as a model. Open Med Educ J 2013;6:48-54.

22. Omorogbe VE, Omuemu VO, Isara AR. Injection safety practices among nursing staff of mission hospitals in Benin City, Nigeria. Ann Afr Med 2012;11:36-41.

23. Bolarinwa OA, Asowande A, Akintimi CI. Needle stick injury pattern among health Workers in Primary Health Care Facilities in Ilorin, Nigeria. Academic Research International. 2011;1: 419-429.

24. Kolade ES. Injection safety: knowledge and practice among health workers. West Afr J Med 2002; 21:70-3. 